\title{
Laboreal
}

Volume $6 \mathrm{~N}^{\circ} 1$ | 2010

Varia

\section{Taylorismo, racionalización, selección, orientación}

Taylorismo, racionalização, selecção, orientação

Taylorisme, rationalisation, sélection, orientation

Taylorism, rationalization, selection, orientation

\section{Henri Wallon}

\section{OpenEdition}

\section{Journals}

Edición electrónica

URL: http://journals.openedition.org/laboreal/9221

DOI: 10.4000/laboreal.9221

ISSN: 1646-5237

\section{Editor}

Universidade do Porto

\section{Referencia electrónica}

Henri Wallon, «Taylorismo, racionalización, selección, orientación », Laboreal [En línea], Volume $6 N^{0} 1$ | 2010, Publicado el 01 julio 2010, consultado el 24 septiembre 2020. URL : http://

journals.openedition.org/laboreal/9221 ; DOI : https://doi.org/10.4000/laboreal.9221

Este documento fue generado automáticamente el 24 septiembre 2020.

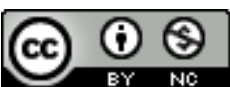

Laboreal está licenciado com uma Licença Creative Commons - Atribuição-NãoComercial 4.0 Internacional. 


\title{
Taylorismo, racionalización, selección, orientación
}

\author{
Taylorismo, racionalização, selecção, orientação \\ Taylorisme, rationalisation, sélection, orientation \\ Taylorism, rationalization, selection, orientation
}

Henri Wallon

\section{REFERENCIA}

Artículo original : Wallon, H. (1947). Taylorisme, rationalisation, sélection, orientation. Technique, Art, Science. Octobre, 5-7.

1 Desde el inicio del Siglo, se expandió en Estados Unidos, Inglaterra y Francia el libro de Taylor sobre "La organización científica del trabajo", que fue objeto de fuertes reacciones. En Francia fue apoyado por un hombre de ciencia : Le Châtelier, profesor del Collège de France, que aplicó los métodos propuestos por Taylor en algunas empresas, más específicamente en los Establecimientos Arbel ; aunque la clase obrera, por lo que cuenta Nerrheim en "La Vie Ouvrière", se mostraba directamente hostil, y Laby, en nombre de la psicotécnica reciente, le realizó severas críticas. En Inglaterra, la oposición parecía llegar, sobre todo, de lado de los ingenieros, que no quedaron convencidos por su colega americano. $\left.{ }^{1}\right]$

2 Taylor marca, sin embargo, un momento histórico importante y tuvo consecuencias significativas, tanto ideológicas como prácticas, o al menos fue un indicador de las profundas transformaciones que influyeron en las relaciones entre el hombre y la tecnología. Hasta entonces parecía que el hombre debía mantenerse ajeno a la tecnología. La creó, la utilizaba, pero como un instrumento al que dominaba siempre. El objeto y el instrumento de la tecnología no podían ser más que cosas, porque se apoyan en las leyes que gobiernan las cosas. Pero ¿la actividad del hombre obedece a estas leyes? Incluso cuando el hombre fue maltratado en su trabajo por ejemplo, bajo la 
esclavitud, donde era utilizado como fuerza motriz; siempre fue tratado como una persona moral. Era castigado como un ser responsable de su vagancia y su torpeza. $Y$ era a estas reacciones globales que era llamado al orden. La ciencia descomponía gradualmente las cosas en sus elementos, reportando la diversidad variable de los efectos en factores físicos definidos ; el hombre, por el contrario, tenía un libre albedrío influenciable, pero en sí mismo indisociable.

3 No hay nada más opuesto a este dogma espiritualista que los principios de Taylor. Estos consagran una observación realizada hace más de cien años sobre las relaciones del hombre y de la máquina por los economistas como Adam Smith, que percibieron una reducción frecuente de la actividad del obrero, por el uso de la máquina, a algunos gestos limitados, y siempre los mismos. Esto era una consecuencia desfavorable de acuerdo a su opinión, pero una regla a generalizar según Taylor. ¿Por qué, de hecho, no incorporar el hombre a la máquina, tratándolo como a ella, si su trabajo en conjunto se identifica, sin distinción posible, en el objeto fabricado ? ¿El acto de fabricación en sí no es una estructura en la que los movimientos del hombre y de la máquina no hacen otra cosa que completarse? Si los movimientos de la máquina se regulan rigurosamente, ¿por qué no los movimientos del hombre? Taylor había imaginado métodos precisos para cortar los metales, ¿por qué comprometer los resultados dejando prevalecer un margen de indeterminación dado por la intervención del obrero? ¿Por qué dejarlo escapar al determinismo cuando el progreso de la ciencia tiende a demostrar su universalidad?

4 La innovación de Taylor, que él consideraba de forma plenamente natural y de una evidencia innegable, es extender a los gestos del hombre las mismas preocupaciones de precisión y de economía que en el uso de la máquina. A cualquier tipo de actividad se le deben corresponder determinados movimientos particularmente bien adaptados que hay que reconocer, seleccionar, enseñar, imponer.

5 Incluso el trabajo más sencillo no puede escapar a esta ley, ni como el de quien transporta una carga pesada. Taylor estudió minuciosamente la maniobra de acarrear bloques de hierro fundido con el objetivo de disminuir la fatiga, aumentando el rendimiento al eliminar los gestos inútiles que funcionan frecuentemente como un obstáculo. Igual que el albañil que levanta un muro más rápidamente si tiene los ladrillos al alcance de la mano. Igual que quien palea carbón o tierra, que debe hacer movimientos de acuerdo a la pala, o, por el contrario, la pala debe tener el cabo con determinado largo, una forma específica y una capacidad relacionada con las características físicas del obrero y con el objeto que carga. Igualmente, en fin, que el obrero metalúrgico. No es suficiente con regular exactamente el torno, sino que debe regular la secuencia de sus actitudes y sus gestos. Pero no es posible hacerlo a priori : el movimiento que se debe realizar hay que estudiarlo en los obreros calificados, analizarlo, cronometrarlo en cada una de sus partes, reconstruirlo y cronometrarlo en su conjunto. Cuando sea finalmente afinado, los instructores lo enseñarán a los obreros y permanecerán alertas de forma permanente para garantizar su correcta ejecución.

6 Este intento, de interés puramente técnico, fue una verdadera revolución. No sólo porque iba en contra de las ilusiones, las rutinas, los excesos espirituales, sino porque contradecían las leyes fisiológicas, psicológicas y sociológicas de la naturaleza humana. Esta oposición tuvo sus frutos. El Taylorismo, impactando de esta forma, sacó del silencio necesidades que se ignoraban a sí mismas. Debido a una especie de movimiento 
dialéctico, con repercusiones alternativas, dio origen a la racionalización industrial, a la selección y a la orientación profesional.

7 La racionalización. Taylor la desarrollo mal, pero la había recomendado, si bien de una forma todavía limitada por un lado, era demasiado extensiva y, por eso, era perversa por otro lado. Cuando recomendaba un mecanismo que liberara al albañil de tener que agacharse para levantar cada ladrillo, o palas diferentes para los que son diestros o zurdos, estaba ajustando la herramienta al obrero, haciendo que con menos fatiga hubiese un mejor rendimiento. De esta forma estaba exactamente en línea con la racionalización. Pero sólo estaba viendo la relación directa entre el instrumento y el gesto. No estaba considerando suficientemente al ambiente del taller $\mathrm{y}$, en primer lugar, el ambiente material, la ventilación, la iluminación, la higrometría, todos aquellos elementos de interés para la fisiología del trabajador y su rendimiento inmediato. Pero, sobre todo, la preocupación casi exclusiva que tenía Taylor con el mecanismo operatorio, le hizo preocuparse únicamente por los movimientos del obrero de la misma forma como consideraba los movimientos de un torno. Su objetivo era desbloquear los momentos útiles y eliminar los tiempos muertos y los gestos parásitos. La maniobra regulada de esta forma, imponía una cadencia por debajo de la cual no se podía caer. Actuando así, este ingeniero cometía una herejía de principiante. Estaba demoliendo la maquinaria humana, que tiene tipos variables de organización de acuerdo con las características de los individuos, y que debe funcionar al ritmo de cada uno de acuerdo con las combinaciones de movimientos que no son iguales para todos, $\mathrm{y}$ que no dejan de estar relacionados con la constitución fundamental de cada uno.

8 El resultado de esta imposición fue el desgaste y la rápida eliminación de los que previamente tuvieron éxito en soportar este régimen y que posteriormente fueron expulsados. En cuanto al resto, se ejerció sobre ellos una especie de selección previa. Al sistematizar aquello que fue primero consecuencia de una exigencia excesiva, llevó a la introducción de un examen de selección en la contratación de los obreros. En esto, Taylor también fue un pionero. Sin embargo, él mismo no comprendió bien su principio. Al preconizar la "organización científica del trabajo" no se liberó completamente de los errores antiguos. La selección no era para él un simple examen de aptitud. Mezcló el interés personal, una vez más de forma torpe. Así como él desconoció la fisiología del hombre, también desconoció su psicología.

Forzando la candencia en el trabajo, exigió más del obrero.

10 ¿Cómo hacer entonces que este consintiese con el aumento del esfuerzo ? La primera vía fue el reemplazo del recalcitrante o del incapaz. Pero también precisaba de otra vía que no fuese el miedo. Aquel que conseguía trabajar con mayor rapidez entonces debía ganar más, pero no proporcionalmente al rendimiento, porque ganar más hacía que el obrero fuese irregular en su trabajo y más vago. La necesidad no podía desaparecer de sus preocupaciones. Era mejor darle una simple bonificación que algunos calculaban que cubría justo el precio de las calorías suplementarias exigidas por el aumento de la intensidad del trabajo.

11 Definitivamente, Taylor no deja de considerar al hombre como una simple maquinaria que se debe utilizar tan económicamente como sea posible. Esta es, además, una intención que declaró formalmente. Ya en el trabajo, el trabajador debía seguir las directrices del empleador. Nada sería más deplorable que dejarle la menor de las iniciativas. La iniciativa lleva a la reflexión, y ésta a la pérdida de tiempo y a la anarquía. Era necesaria una oficina de métodos para la regulación soberana de los 
gestos, las velocidades y los premios. Cada cual dependía individualmente de esta oficina. Entre los obreros, no se admitía ninguna solidaridad de intereses. Todos eran tratados como maquinarias del mismo modelo, pero cada uno era una maquinaria completamente diferente de las otras.

Esta mutilación del trabajador, expresamente deseada por Taylor, debía naturalmente volverse en contra del sistema, porque se encuentra en oposición con las necesidades esenciales del ser humano. La fisiología hizo rápidamente justicia de los gestos y los ritmos impuestos. La psicología reveló por qué llamado al interés puramente individual también lleva al fracaso. El hombre aislado estaba a la defensiva. No sabía entregar más que una parte más o menos reducida del trabajo. Las energías estaban retenidas. Para que se liberen, era necesario un verdadero compromiso del trabajador con su tarea. Este compromiso resultaba imposible debido al egoísmo de los métodos que Taylor impuso a los trabajadores. Como fue mencionado hace algunos años por los psicólogos soviéticos, el régimen capitalista está hecho de forma tal que nunca podrá liberar el potencial de trabajo que existe en cada persona.

Al ser indiferente, al ser realmente hostil a las necesidades del ser humano, el Taylorismo no podía descubrir la orientación profesional, que se opone a la selección como el punto de vista del individuo puede oponerse a las exigencias únicas de una tarea determinada. Esta, tiene como objetivo encontrar para cada cual el empleo que mejor le conviene, de acuerdo no sólo con sus aptitudes, sino también a sus gustos e intereses mejor comprendidos. De esta forma, sirve también al interés general de evitar ese residuo de menor calidad que resulta de la selección y que arriesga de pesar en la economía del país, solo en beneficio de algunas empresas privilegiadas.

Sin embargo, el contacto con la realidad impuso a Taylor algunas observaciones que hicieron presagiar a la orientación profesional. Así, las separadoras de canicas que él detectaba como las más rápidas, no eran habitualmente las más inteligentes. A una inteligencia mediocre pueden corresponder aptitudes más o menos incompatibles con un espíritu más despierto. Era evidente que el papel de la orientación era utilizar esas diferencias en sentido inverso para distribuir distribución de cada cual al puesto de trabajo con más posibilidades de éxito individual.

Por el carácter grosero de estos procedimientos, muchas veces contrarios a la naturaleza fisiológica y psíquica del hombre, el Taylorismo suscitó dificultades y reacciones que fueron el punto de partida de importantes progresos. Él, finalmente, contribuyó para imponer aquello a lo que tendía a desconocer o suprimir, revelándose en un claro ejemplo de aquellas contradicciones que se resuelven en descubrimientos o en nuevas etapas. La mecanización de los trabajadores, explícitamente deseada por Taylor, se transformó en una estricta necesidad de hacer valer el derecho de todas las exigencias de la naturaleza humana, exigencias que no son sólo fisiológicas sino, también, psíquicas, sociales y morales. 


\section{NOTAS}

1. En sus libros "La crise du progrès" y "Problèmes humains du machinisme industriel", Georges Friedmann hizo un estudio notable del Taylorismo. http://laboreal.up.pt/revista/artigo.php? id $=37 t 45 n S U 5471122987295752361$ 